DOI: 10.20472/IAC.2017.031.058

\author{
CHARLES WILD \\ LRM Analyst, United Kingdom
}

\title{
STUART WEINSTEIN
}

Coventry University, United Kingdom

\section{“BY FAILING TO PREPARE, YOU ARE PREPARING TO FAIL": THE IMPORTANCE OF TEACHING LEGAL RISK MANAGEMENT, GOVERNANCE AND COMPLIANCE TO LAW STUDENTS}

\begin{abstract}
:
High profile corporate scandals have not only taught us that the loss of reputation can have a significant, if not, fatal effect on a company but also ensured that the study and implementation of legal risk management is at the forefront of the UK's business and legal sectors. The significance of the complex assortment of new and often contradictory laws and regulations with which companies are faced in today's global business environment should not be underestimated.
\end{abstract}

Many international companies recognise this and invest heavily in implementing internal mechanisms and controls to detect and prevent compliance breaches. However, such systems and controls cannot succeed without the development of a strong compliance culture that gets "buy-in" from all levels of a business. At the heart of this compliance culture is a company's legal and compliance manager(s).

Effective legal risk management and compliance requires a company's legal and compliance manager(s) to gain a substantive knowledge of business and societal risks, awareness and insight into regulation and regulatory changes as well as an understanding of the potential impact of regulation on their organisation. Once these risks have been identified, and appropriate regulatory challenges ascertained, a business must develop, implement and communicate internal policies and ensure that effective control systems are also in place.

In order to prove both efficient and effective, a business' legal and compliance manager(s) must draw informed links between regulation and the formulation of sound internal policies related to risks and controls at all relevant levels of their organisation. They must also implementation appropriate procedures to support such policies. Consequently, in order to be effective, a company's legal and compliance manager(s) must not just identify problems but, more importantly, draw upon proven solutions to ensure success. The legal risk management process relies on a business' ability to manage processes, implement change, track issues, screen potential clients, partners and employees and to implement appropriate remediation.

The pressure on management to ensure that a business operates in a compliant way is considerable, and growing. Managers must be permanently on their guard against things going wrong and, as such, are reliant on their legal and compliance manager(s) being ever vigilant and seeking to reduce risk to a minimum. The authors argue that in order to gain a well-rounded, informed business-focused preparation for work within the legal sector, every law student should, at some stage, gain a grounding in Legal Risk Management, Governance \& Compliance. 


\section{Keywords:}

Legal Education

Legal Risk Management, Governance \& Compliance

Multi-disciplinary

JEL Classification: K20, 123 


\section{Introduction}

The night was perfect. The stars were out in force and shining brightly for all to see. The fairy tale was going according to plan. This was the real La La Land. Then, it all started to go horribly wrong. The incorrect award envelope was handed to Mr Beatty. An error blamed on Mr Cullinan, a Price Waterhouse Coopers employee, who had just tweeted a picture of the best actress winner, Emma Stone. Mr Beatty proceeded to open the envelope, and paused. Was this for dramatic effect? Mr Beatty had just seen Best Actress: Emma Stone for La La Land. He paused again. Something appeared to be wrong. He showed the contents of the envelope to his co-host, Ms Dunaway. They proceed to announce La La Land as the winner of best picture (Kennedy \& Grierson 2017). The rest, as they say, is history. Described as the biggest mistake in 89 year history of this event, it is also perhaps the most interesting thing to happen at the Oscars since Jack Palance performed one armed push-ups back in 1991.

However, as with many high profile corporate scandals, this is a perfect example of Legal Risk Management, Governance \& Compliance in action. Immediately following the event, Price Waterhouse Coopers, owned the mistake; without reservation (Gonzalez \& Thomas 2017). Their apology included the fact that 'we are currently investigating how this could have happened, and deeply regret that this occurred' (Hill 2017). A human error was made. The incorrect award envelope was handed over. Price Waterhouse Coopers took responsibility, quickly and publicly. It is a valuable lesson for any company.

No person, company or organisation is perfect. Mistakes happen. Perfection is not always achieved and, when this occurs, it is important that we recognise it, take ownership of the event, and seek to ensure that such errors are corrected. It is the response that a company makes which can be the defining moment in the maintenance of its public reputation and retention of its clients. The other part of this process is the way in which a company seeks to provide a resolution and assurances that delivery of perfection will be resumed. This is already underway. It was reported that the two accountants responsible for the mistake, (Mr Cullinan and Ms Ruiz), will no longer be employed to do this job again (Lang \& Stedman 2017). However, it is clear that further assurances are needed as it has also been reported that the Academy Awards' relationship with the accountancy firm is now under review (Dean \& Furness 2017).

To put this into context, bar a minor mistake in 1964, Price Waterhouse Coopers have gone for 83 Awards Ceremonies without a mistake. However, we now live in an era of social media whereby every action, and especially every error, is scrutinised and second-guessed. However, the majority of this focus will be upon someone to blame. The purpose of Legal Risk Management, Governance \& Compliance is to understand what went wrong, to reflect upon the processes and procedures that were in place and, where necessary, to review practice in order to ensure that every link (person) in 
the chain appreciates what needs to be done so as to avoid a repeat of that mistake. Hardly the stuff of rolling news and twitter accounts.

\section{The List of Unknowns}

We know that Mr Cullinan handed over the incorrect award envelope to Mr Beatty. We know that he had just tweeted a picture of the previous winner, Emma Stone. We know that the President of the Academy Awards, Ms Boone Isaacs, blamed the error on 'distraction'. However, there are also a significant number of unknowns.

1. Had Mr Cullinan and his colleague, Ms Ruiz, received training and/or instructions on how to undertake their roles?

2. If so, was this delivered by Price Waterhouse Coopers, the event organisers, or by both?

3. If not, why not? A constant review of practice should be a natural part of any ongoing activity.

4. Had Mr Cullinan and Ms Ruiz been encouraged and/or instructed to tweet during the event?

5. If so, was this a promotional opportunity for Price Waterhouse Coopers and, if it was, it is reasonable to permit them to take the blame for the mistake?

6. If not, and if this was an example of an employee (or rather a PWC partner) undertaking an unauthorised activity, had Price Waterhouse Coopers taken sufficient measures to ensure that it shouldn't have happened both prior to, and during the event?

7. In other words, had Price Waterhouse Coopers undertaken an effective risk assessment to ensure that as many eventualities as possible had been considered and mitigated against?

8. Turning to Mr Beatty and Ms Dunaway, had they been briefed on what to do in the event of a mistaken awards envelope being handed to them?

9. If so, was this delivered by Price Waterhouse Coopers, the event organisers, or by both?

10. If not, why not? The effectiveness of any process or procedure is only as robust as its weakest link. In this case, whilst there might have been an effective review of the back office, (Mr Cullinan and Ms Ruiz) had the front of house personnel (Mr Beatty and Ms Dunaway) been briefed effectively?

11. Finally, who took the decision to switch from the use of gold paper with white labels in 2016 to that of red paper with gold letters in 2017? Why was the decision taken when it is acknowledged that the latter is considerably harder to read in dim backstage lighting than the former format?

The list of questions and queries could, quite easily, go on and on. In an interview the following Monday morning, Price Waterhouse Coopers US Chairman, Tim Ryan, told USA Today that 'we made a mistake. What happened was, our partner on the left side of the stage, Brian Cullinan, he handed the wrong envelope to Warren Beatty. And 
then the second we realized that we notified the appropriate parties and corrected the mistake" (Calvario 2017). However, in a statement released by Price Waterhouse Coopers later that day the company simply stated "once the error occurred, protocols for correcting it were not followed through quickly enough by Mr Cullinan or his partner" (Gonzalez \& Thomas 2017).

Whilst precise details of these protocols have not been made clear, it is understood to include Mr Cullinan and Ms Ruiz memorising the names of the winners so that they are able to respond quickly in the event that an incorrect name is read out by the presenters or so that they are able to share the winner's name with the presenters in the event that something happens to the envelopes (Reuters 2017). Indeed, according to Tim Ryan, Price Waterhouse Coopers US Chairman, 'Immediately when it was announced, again, because of our mistake, both our partners who knew who the winner was - and they're the only two who know - they realized the mistake had been made and they began to notify the appropriate people... Unfortunately that took enough time to get through two-and-a-half acceptance speeches' (Calvario 2017).

Mr Ryan is correct, in part. On the night, the cast and crew of La La Land stood up, congratulated one another, walked on to the stage and, once they had been handed the Oscar for Best Picture, three producers had had the opportunity to speak on stage before the error was announced. However, where accounts differ is that the ceremony's stage manager, Gary Notoli, is quoted as stating that Mr Cullinan and Ms Ruiz had both frozen backstage when things went wrong and, ultimately, they had to be pushed onstage in order to correct the situation. Notoli stated, "We watched for about 10 more seconds, and during that entire time, Martha was no more than five feet away from us...she did not try to get my attention, she did not say anything. And she's supposed to have memorised the winners... We had to push them on stage, which was just shocking to me" (Reuters 2017). The ceremony's stage manager went on to note "We know that Brian (Cullinan) was taking pictures backstage when he should not have been, and not paying attention...And there was the new design of the envelope, which we had complained about to the Academy."

Perhaps most damaging of all to Price Waterhouse Coopers is an interview conducted by Mr Cullinan and Ms Ruiz with the Huffington Post a week before the ceremony. When asked what would happen if a presenter announced the incorrect name, they told the news website that the exact procedure for dealing with such a mistake was unknown because such errors had never been made before (Kennedy \& Grierson 2017).

\section{The Timeline}

There are also a number of inconsistencies which have come to light in terms of the timeline and personal accounts of what occurred. In this regard the sheer volume of social media which recorded the event and which has subsequently been evaluated 
by analysts has provided an almost unique opportunity to revisit this most public of failures and to piece together events as they unfolded.

Prior to the ceremony, Mr Cullinan is recorded as saying, "It's such a long-term relationship that we know intricately how everything works, the timing of it, the process that we use, and they have absolute trust in us and what we do" (Dean \& Furness 2017). Furthermore, in a promotional video highlighting the company's role in the ceremony, he is quoted as saying "the reason we were even first asked to take on this role was because of the reputation PwC has in the marketplace for being a firm of integrity, of accuracy and confidentiality" (Hill 2017).

However, at $8.53 \mathrm{pm}$, as the Best Actress montage was playing on stage, Mr Beatty was photographed backstage hugging the Best Actor winner, Casey Affleck, who had just come off stage with his award. The photograph shows that in Mr Beatty's hand he is holding a white notecard with his Best Picture introduction on it. Mr Cullinan is standing immediately next to Mr Beatty on his right. Mr Cullinan is clearly carrying two envelopes in his hand. It is claimed by the organizers that the odds are very likely that these two envelopes represent the last two categories of the night: Best Actress (which he later handed to Mr Beatty) and Best Picture. Mr Cullinan had just handed his copy of the Best Actor envelope to presenter Brie Larson minutes before (Yee \& Oldham 2017). He was also holding his mobile phone together with the two envelopes.

At $8.54 \mathrm{pm}$, the Best Actress montage was still playing on stage. Backstage, Mr Beatty watched the monitor with Mr Cullinan immediately to his left.

At $9.03 \mathrm{pm}$, Ms Dunaway and Mr Beatty walk on to the stage in order to present the final category of the evening, that of Best Picture. A photograph shows Emma Stone stands in the wings of the stage, looking at the Oscar she had just won for Best Actress.

At 9.04, Ms Dunaway and Mr Beatty introduce the Best Picture. Backstage, another photograph shows Emma Stone having her photograph taken by a number of people, including Mr Cullinan.

Thirty seconds later, a photograph shows Mr Cullinan tweeting his photograph of Best Actress Winner, Emma Stone whilst, on stage, the Best Picture montage plays.

At $9.05 \mathrm{pm}$, Mr Cullinan's tweet of Emma Stone is posted on Twitter. He also takes the opportunity to hashtag Price Waterhouse Coopers in his post. The tweet has since been deleted from his account, though it is still viewable in a cached page on Google (Gonzalez \& Thomas 2017). 
At 9.08 pm, Ms Dunaway incorrectly announces La La Land as winner of the Best Picture category. The picture clearly shows a confused and slightly distressed $\mathrm{Mr}$ Beatty next to her.

Three and a half minutes later, there is a picture of $\mathrm{Mr}$ Cullinan on stage next to $\mathrm{Mr}$ Beatty and the cast of La La Land. His colleague, Ms Ruiz hands the correct envelope to him. The aftermath is now Hollywood history.

The reason that these photographs are so interesting is that they reveal the risk faced by any organization; that the recollection of people and official explanation for failure may not mirror the reality of what actually occurred. The photographs show $\mathrm{Mr}$ Cullinan engaged on his phone shortly before the error occurred. This we knew. However, he is also photographed mixing two red envelopes backstage whilst standing next to Mr Beatty and Best Actor winner, Casey Affleck, who had just exited the stage. This photographic evidence would appear to dispute Price Waterhouse Coopers official explanation that Mr Cullinan had grabbed the wrong envelope from a 'backup pile' and clearly shows that he was in possession of two envelopes (Yee \& Oldham 2017). In other words, Mr Cullinan held both the Best Actress envelope, which was handed to Mr Beatty, and the Best Picture envelope, which was not.

\section{Own the mistake and be certain of the facts}

As noted earlier, the purpose of Legal Risk Management, Governance \& Compliance is to understand what went wrong and to reflect upon the processes and procedures that were in place. It would appear that social media, rather than members of the Price Waterhouse Coopers team, have provided clarity as to what actually took place. It would also appear that Price Waterhouse Coopers' explanation of human error was only partially correct. If the role of Legal Risk Management, Governance \& Compliance is to enable a company to review practice in order to ensure that every link (person) in the chain appreciates what needs to be done so as to avoid a repeat of that mistake, then an accurate understanding of what occurred is essential.

Therefore, whilst Price Waterhouse Coopers is to be commended on its immediate public ownership of the mistake, their explanation needed to be provided once an adequate investigation of the facts had taken place so as to ensure that an accurate assessment of the events is presented. Otherwise, the risk faced by any organisation is that social media will provide the data for a contradictory timeline to be pieced together by external individuals who have nothing to lose by questioning the adequacy of a business' internal processes and procedures. Indeed, it is with a certain amount of irony that Mr Cullinan is quoted as saying in a pre-ceremony promotional video, "it's really symbolic of how we are thought of beyond this role and how our clients think of us, and I think it is something we take very seriously and take a lot of pride in" (Hill 2017). The challenge for Price Waterhouse Coopers is to not only own the mistake, 
conduct a thorough investigation so as to ensure that it does not occur again but, most importantly, to manage public perception and the reputation of its brand.

The error which arose during the 2017 Oscars raises a number of common sense themes which, at heart, is what Legal Risk Management Governance \& Compliance is all about. Sooner or later, things will go wrong. We all think about it and consider what we would have done if we had been in the position of Mr Beatty and Ms Dunaway. Sooner or later, a company, its employees and its managers will encounter a problem. The question arises as to whether the company has prepared for such an eventuality? Does it have a contingency plan in place that will ensure a swift and effective resolution? Are all of the company's staff, at every level involved, aware of this plan and the part that they are expected to play in it? Most importantly of all, does the company in question appreciate the implications, in terms of public reputation and client retention, of a failure to address a problem quickly and publicly? To quote Benjamin Franklin, 'by failing to prepare, you are preparing to fail'.

\section{The importance of Legal Risk Management, Governance and Compliance}

Recent high profile corporate scandals have not only taught us that the loss of reputation can have a significant, if not, fatal effect on a company but have also ensured that the study and implementation of legal risk management is at the forefront of the UK's business and legal sectors (Weinstein \& Wild 2016). The significance of the complex assortment of new and often contradictory laws and regulations with which companies are faced in today's global business environment should not be underestimated.

Many international companies recognise this and invest heavily in implementing internal mechanisms and controls including sophisticated information technology systems designed to detect and prevent compliance breaches (Weinstein \& Wild 2013). However, such systems and controls cannot succeed without the development of a strong compliance culture that gets "buy-in" from all levels of a business. At the heart of this compliance culture is a company's legal and compliance manager(s).

In order to undertake such a role effectively, the legal and compliance manager(s) must not only appreciate the subtleties of each of the three areas, but also the way in which they interact with one another as well as with the business and societal environments within which they sit. The areas may be summarised as follows:

1. Legal risk management (LRM) involves the identification of issues such as legal liability and compliance failure, mitigation and the balancing of risk in all its forms. This involves a company's legal advisor(s) pointing out where and how things can and might go wrong, appreciating the extent of any negative impact if problems 
arise, devising plans to cope with threats and putting in place strategies to deal with the risks either before or after their occurrence.

2. By contrast, legal governance is the establishment, execution and interpretation of processes, procedures and rules that have been put into place by a company's legal department in order to ensure a smoothly run legal department and company.

3. Finally, and perhaps the one with which most people struggle to appreciate fully, compliance can be described as anticipating, identifying and resolving regulatory and ethical risks within a company, and as re-designing systems with the aim of improving compliance.

Effective legal risk management and compliance requires a company's legal and compliance manager(s) to gain a substantive knowledge of business and societal risks, awareness and insight into regulation and regulatory changes as well as an understanding of the potential impact of regulation on their organisation. Once these risks have been identified, and appropriate regulatory challenges ascertained, a business must develop, implement and communicate internal policies and ensure that effective control systems are also in place (Weinstein \& Wild 2013).

However, in order to prove both efficient and effective, a business' legal and compliance manager(s) must draw informed links between regulation and the formulation of sound internal policies related to risks and controls at all relevant levels of their organisation. They must also implement appropriate procedures to support such policies.

Consequently, in order to be effective, a company's legal and compliance manager(s) must not just identify problems but, more importantly, draw upon proven solutions to ensure success. Therefore, it is essential that anyone who has studied law and subsequently qualified as a solicitor or gone on to become an in-house legal manager, to understand more than pure legal theory or the standard curriculum deemed sufficient by the Solicitor Regulation Authority and Law Society to practice law in England and Wales. Students require a grounding in the business and societal environments within which they will work and, most importantly, advise their clients as to the actions, strategies and plans which should be pursued. Far too often advice may be limited to the familiar legal liability risk facing a company, at the expense of underestimating the impact on stakeholder confidence in a business, the emergence of trial by social media, or the negative consequences of public perception on a business' brand.

The pressure on management to ensure that a business operates in a compliant way is considerable, and growing. Managers must be permanently on their guard against things going wrong and, as such, are reliant on their legal and compliance manager(s) being ever vigilant and seeking to reduce risk to a minimum (Weinstein \& Wild 2013). It is drawing this linkage between regulation and the formulation of sound policies related to risks and controls at all relevant levels of the organisation and the 
implementation of procedures to support such policies that are at the heart of the authors contention that every law student should, at some stage, gain an insight into Legal Risk Management, Governance \& Compliance.

For instance, a company's Board of Directors can only act on what it knows. If it doesn't know something, it cannot make an informed choice. In addition, managers rely on legal and compliance manager(s) to not only identify potential and/or actual problems, but to provide solutions and suggestions as to how such problems may be avoided, addressed or even mitigated (Weinstein \& Wild 2016). Finally, the vast majority of regulators rely on reliable and accurate information being disclosed by companies in order to regulate commercial entities. As such, internal data collection not only needs to be implemented but also undertaken in a way that is beneficial to everyone concerned. Reports which outline data but which is of little or no value to either the business or the regulator is a waste of resources and goes to highlight the inevitable failings of the company in question. With these legal, business and societal environments in mind, the legal risk management process relies on a business' ability to manage processes, implement change, track issues, screen potential clients, partners and employees and to implement appropriate remediation.

Placing the Price Waterhouse Coopers' Oscars fiasco into the context of the Legal Risk Management Governance and Compliance discipline, it is evident that this is an episode of failed governance procedures resulting in significant reputational harm, e.g. the United Express Flight 3411 incident of 9 April 2017 comes to mind. Roy Schapira (2015) speaks of a "reputational theory of corporate law" by suggesting that the main impact of corporate law is not in imposing sanctions, but rather in producing information. In this regard, when an event such as the Oscars' gaffe takes place live before the world's largest television audience there is a stronger reputational sanction involved for Price Waterhouse Coopers than any fine imposed by a regulator or lawsuit lost.

\section{Conclusion}

As noted earlier, no manager, company or organisation is perfect. Mistakes will, and do, happen in real life. Whilst the classroom teaches students about perfect models of behaviour or encourages them to provide the perfect answer to a problem, this does not mirror the environment in which they will work. Perfection is not always achieved and, when errors arise, it is important that they are able to recognise it, take ownership of the event, and seek to ensure that such errors are corrected. However, in order to be truly effective, the solutions to such errors will not always fall 'perfectly' within the legal, business or public relations sphere. In real life, people will need to look beyond the familiar in order to provide the most effective solution to a problem. 
It is the response that a company makes to a problem which can be the defining moment in the maintenance of its public reputation or its retention of clients. The other part of the process is the way in which a company seeks to provide a resolution and assurances that delivery of perfection will be resumed. Once again, to be effective, a company legal and compliance manager(s) must look beyond solutions and work with a wider team across all areas of the company in order to ensure that this latter part is effectively undertaken. However, unless an individual has encountered such approaches whilst a student, it will prove extremely challenging for them to implement it is practice, especially given the inevitable pressures that will accompany such situations.

Returning to the 2017 Oscars ceremony, Price Waterhouse Coopers immediately took responsibility and apologised for the mistake. They also announced that the two senior accountants responsible for the mistake would no longer be employed to do this job again. However, on reflection, the company has a lot to learn if it is to avoid a repetition of this mistake in the future and, perhaps more importantly, if it is to rebuild public confidence in its brand. Ahead of the ceremony, it was not advisable for $\mathrm{Mr}$ Cullinan and Ms Ruiz to state publicly that there was no contingency plan in place in the event of an error. Equally, it was not advisable for them to be publically photographed ahead of the ceremony along with celebrities. In retrospect, these lapses have come back to haunt both them and Price Waterhouse Coopers.

Similar faux pas were made during the ceremony. Taking photographs and tweeting them during the ceremony may have sounded like an excellent publicity stunt ahead of the event. If all had gone smoothly, it may very well have proved to be beneficial to Price Waterhouse Coopers. However, a mistake was made. Moreover, there are numerous photographs all over social media recording the timeline minute -by-minute up to that mistake taking place. In retrospect, Mr Cullinan will look at the photograph of him tweeting his picture of Emma Stone and he will wish that someone had stopped him. However, it is now too late. Legal Risk Management, Governance and Compliance is about anticipating problems and ensuring that unnecessary, avoidable risks have not been taken by a company, or its employees.

\section{References}

Calvario.L, 27 February 2017, 'Price Waterhouse Coopers chairman says Best Picture gaffe was a "human error"', Deadline Hollywood, http://deadline.com/2017/02/oscar-best-picture-mistakepricewaterhousecoopers-chairman-human-error-brian-cullinan-1202018174/

Dean.S \& Furness.H, 27 February 2017, 'PwC in crisis meeting with Academy over 83-year contract following amazing Oscars blunder', The Telegraph, http://www.telegraph.co.uk/business/2017/02/27/global-financial-giant-pwc-blame-oscars-mix-up/

Gonzalez.S \& Thomas.M, 28 February 2017, 'PwC: We failed the Academy in bes t picture mess up', http://edition.cnn.com/2017/02/27/entertainment/oscars-mix-up-pricewaterhousecoopers/ 
Hill.L, 27 February 2017, 'Price Waterhouse Coopers issues statement after Oscars mistake robs Moonlight of its moment', Los Angeles Times, http://www.latimes.com/entertainment/la-oscars2017-89th-academy-awards-pricewaterhouse-coopers-issues-1488184837-htmlstory.html

Kennedy.M \& Grierson.J, 27 February 2017, PwC issues apology after Oscars best picture envelope mistake', The Guardian, https://www.theguardian.com/film/2017/feb/27/pricewaterhousecoopersissues-sincere-apology-for-oscars-blunder

Lang.B \& Stedman.A, 2017, 'Oscars will no longer work with PwC accountants involved in Best Picture Flub', Variety, http://variety.com/2017/film/news/oscars-drop-pricewaterhousecoopersaccountants-academy-1202000145/

Reuters, 2 March 2017, 'PwC accountants behind Oscars Gaffe now need private security', http://fortune.com/2017/03/02/oscars-2017-pwc-accountants-security/

Shapira, Roy, 13 April 2015, 'A Reputational Theory of Corporate Law', Stanford Law \& Policy Review, Vol. 26, No. 1, 2015, https://papers.ssrn.com/sol3/papers.cfm?abstract id=2593330

Yee.L \& Oldham.S, 2017, New Photos show PwC accountant tweeting, mixing envelopes backstage at Oscars, Variety, http://variety.com/2017/film/news/oscar-best-picture-gaffe-brian-cullinanenvelope-1201999283/

Weinstein.S \& Wild.C, 2013, Legal Risk Management, Governance and Compliance: A guide to best practice from leading experts', Globe Law and Business

Weinstein.S \& Wild.C, 2016, Legal Risk Management, Governance and Compliance: Interdisciplinary case studies from leading experts, Globe Law and Business 